\title{
SIGNALLING IN THE TURKISH-SYRIAN WATER CONFLICT
}

\author{
Serdar Güner \\ Bilkent University
}

\begin{abstract}
This paper proposes a simple two-person game of one-sided incomplete information in extensive form to understand strategic choices made in the Turkish-Syrian linkage between water and terrorism. Turkish intelligence established Syrian support of a terrorist group that aims at an independent Kurdish state in eastern Anatolia. Yet, Turkey frequently stipulates the cessation of this support for negotiating with Syria a water agreement over the Euphrates. The game presents Turkey as a player having superior information. Syria is assumed to be uncertain about Turkish preferences with respect to the mutual conflict. This analysis identifies three pooling equilibria indicating that Syrian beliefs do not matter.
\end{abstract}

Water means life and the survival of nations, especially in the Middle East. In transboundry river basins like the Nile, Jordan, and Euphrates, disputes over the upstream and downstream utilization of river water hinder cooperation among riparians. Hence, riparian control over scarce water resources creates yet another dimension of international conflict in this arid region.

An international law of transboundry water courses and commonly accepted principles to regulate and control water conflicts do not exist. Kilgour and Dinar (1994: 1-2) list several rules to resolve water conflicts. The Harmon doctrine gives the riparians the right of absolute sovereignty over the flow of the river on their territory. The principle of territorial integration partitions riparian rights of exploitation equally. The principle of the equitable utilization allows riparians to use the river water provided that they cause no harm to one another. The mutual use principle permits any riparian to register objections to others' exploitation of the river water and to claim compensation. Finally, the linkage principle indicates that the resolution of water conflicts is linked to concessions in other issues.

LeMarquand (1977) indicates that water conflicts are linked to other issues of riparian contest in all river basins. For example, the solution to Jordan waters issue was linked to the Palestine problem (Lowi, 1993: 100). Similarly, Syria linked the amount of water it let flow from the Euphrates to Iraq to the Iraqi approval of its policy towards Israel after the Yom Kippur War (Lowi, 1993: 59). Syria reduced the flow of the Euphrates at that time, as Hafez Al-Asad retal- 
iated against Saddam Hussein, who was opposed to his policy towards Israel. This is not the only case of issue-linkage in the basin. Iraq linked the amount of oil it let flow through the pipeline in Turkish territory to the Turkish exploitation of the Euphrates. After the Turkish decision to build the Karakaya Dam on the Euphrates in 1977, Iraq responded the same year by cutting off its oil supply to Turkey.

In these examples we observe that only one riparian links water to another issue or vice versa: Syria links water to the Iraqi approval of its Israeli policy or Iraq links oil to water. Yet, both Turkey and Syria do so in their interactions. Turkish intelligence has established Syria's support of the Kurdish Workers Party, PKK (Partiya Kerkarani Kurdistan) that aims at the creation of a Kurdish state in Southeastern Turkey. Syria, having granted the leader of the PKK the status of a political refugee, provides him with shelter. It also allows the organization to have military bases in the Beqaa Valley, a region under its control. The headquarters of the PKK are allegedly in Syria.

Turkey, in its bilateral negotiations with Syria on the waters of the Euphrates, usually brings up the issue of Syrian support to the PKK. While Syria presses for a Turkish water concession, allocating at least $700 \mathrm{~cm} / \mathrm{s}$ (cubic meters per second) of the river flow entering its territory, Turkish leaders in turn declare that no solution to the water problem can be found unless Syria changes its policy on the PKK. In its turn, Syria tacitly communicates that it will continue to support the PKK unless Turkey concedes in the issue of water. Thus, the issuelinkage results in a mutual conflict, while Turkey and Syria remain intransigent.

This paper assesses, in the framework of a simple signalling game, the implications of Syrian uncertainty about Turkish preferences with respect to the mutual conflict. Turkey moves first by choosing to agree to a water treaty or not. Here, Turkey is assumed to be fully informed about the Syrian objectives and policy. After the Turkish choice, Syria chooses between supporting the PKK or not, without knowing the Turkish preference ordering. The game ends after the Syrians make their choice. Our problem is to identify the outcome(s) of this issue-linkage, including the mutual conflict, under information conditions which approximate reality. Accordingly, we develop hypotheses by proposing a non-cooperative game in extensive form where Turkey possesses information that Syria lacks.

There are several reasons why this research question was posed. First, as Frey (1993) indicates, there is a need for theory-building to explain conflict and cooperation on water issues. These issues 
become progressively crucial given global changes in the environment. Second, game-theoretic models of water issues are rare. Rogers (1993), Dinar and Yaron (1986), Tijs and Driessen (1986) and Young et al. (1982) build cooperative games to compute the stable distribution of water quotas given river supplies. However, to assume international agreements as binding contracts is questionable. In international relations, countries cooperate out of self-interest. They defect whenever they do not profit from an agreement. Third, the element of uncertainty, which plays an important role in international politics, is absent in all these game models. Finally, none of these works concentrate on linkages.

The Turkish-Syrian issue-linkage becomes more fundamental than sharing waters of the Euphrates given the multiplicity of conflicts over sovereignty between the two countries and the nonexistence of an exogenous mechanism for enforcing contracts and commonly accepted rules for property rights in the case of transboundry water courses. Consequently, Turkey does not choose between different treaty proposals in its move. A Turkish-Syrian cooperation should arise from the rules of the game alone, not through an exogenous mechanism. This excludes the search for water levels acceptable to both sides in an equilibrium and the construction of a cooperative game that assumes agreements as binding contracts.

We obtain three pooling equilibria as answers to our research question. They specify that Turkey, whatever its type, does not agree to sign a water treaty given the best replies of Syria. The first equilibrium indicates that, regardless of Turkey's type, Syria's best reply would be to withdraw its support from the PKK. However, this does not describe the empirical world since the Turkish intransigence and security agreements did not result in curbing Syria's support of subversive activities. The second equilibrium specifies that Syria supports the PKK if Turkey agrees but not otherwise. Here, the Turkish refusal is in part due to Turkey's expectation of continued Syrian support of the PKK once Syria obtains its preferred solution to the water problem. Turkey expects that such a Syrian policy can only aim to annex Hatay, the Sandjak of Alexandretta, a part of French-mandated Syria until 1939, when the province was united with Turkey as a result of a plebiscite. Syria claims that this decision is invalid. The third equilibrium describes the current situation. Regardless of the cost it suffers in the mutual conflict, Turkey does not compromise, and, Syria, as a reaction, supports the PKK. Here, Turkey again expects that Syria will cheat by asking further concessions if given a 
water agreement, and Syria does not believe Turkey can sustain the cost and therefore supports the PKK.

These answers point out that, given the same information conditions and sequences of action, Turkey's policy does not vary, but Syria's policy changes according to different Syrian beliefs about Turkey. So, Turkish choice of no agreement is not sensitive to different Syrian perceptions. Contrary to this, reacting to Turkey's policy, Syria can find different sets of best replies. Therefore, incomplete information of Syria about Turkey has no effect upon the consistent Turkish policy.

The paper proceeds in five sections. The next one gives more details about the conflict. The subsequent section presents the game. The equilibria are computed in the third section. The fourth one interprets these equilibria followed by an assessment of the conflict.

\section{TURKISH-SYRIAN CONFLICTS}

\section{The Issue of Water}

The Euphrates rises in Eastern Anatolia and then flows through Syria and Iraq. Turkey is the upstream, Syria the midstream, and Iraq the downstream riparian. More than eighty percent of the river is generated in Turkey. Syria's contribution is around ten percent. Iraq does not contribute to the runoffs.

In the early seventies, Syria and Turkey began to harness the waters of the Euphrates with large scale irrigation and hydro-electric power generation projects. For example, the Turkish project of GAP (the Turkish acronym for the Southeastern Anatolian Project) is of a colossal dimension, including seven projects on the Euphrates and six on the Tigris. It envisages the irrigation of 800,000 hectares around the year 2030 and even a change in the environment. Its completion will eventually reduce the water flow to Syria to $300 \mathrm{~cm} / \mathrm{s}$. This implies a lowering in the quality of water due to its upstream use for agricultural and industrial purposes. In addition, the demands of Turkey, Iraq, and Syria necessitate more water in sum than the river can supply. In such a context, the dams are perceived as threats, not as means to store water.

However, given the high rate of seasonal fluctuation of the Euphrates, water storage is a vital necessity in the basin. The dams built upstream do not necessarily work against the interests of the midstream and downstream riparians. The Boulder dam in the basin of the Colorado river (U.S.A.) provides an example. The upstream dam 
works as a water storage not only for the US but also for Mexico, even in the driest periods, at no cost to Mexico. This illustrates that the utility of controlled water quantity is greater than the utility of uncontrolled water of greater volume (Bilen, 1993). If one also takes into account that the Euphrates floods are not ideal for crop production, the utility of regulating the water supply for all riparians can be better appreciated.

Nevertheless, such arguments do not persuade the riparians under the present mood of suspicion, historical claims, and rivalries. The riparian positions, with respect to the solution of the problem, illustrate further the depth of the water conflict. Syria and Iraq claim that they have been using the Euphrates and the Tigris for millennia, and, therefore, they have historically acquired rights over them. Syria suggests that the Euphrates must be shared according to a formula computed by riparians' demands given the river's capacity. Contrary to this position, Turkey proposes a three-stage plan for both the Euphrates and Tigris that envisages cooperation among Syria, Turkey, and Iraq about the quality and quantity of the water, lands they control, and development of modern systems of irrigation such as drip technology. These positions show the difficulty of finding a common ground.

\section{The Issue of Territory}

The common use of a transboundry water course, with its potential of creating distributive conflicts between upstream and downstream riparians, expands the sources of contention in Turkish-Syrian relations. For example, Syria never recognized Turkish sovereignty over Hatay (the Sandjak of Alexandretta). This region was a part of the French mandated Syria and decided as an autonomous entity to join Turkey in 1939.

A direct implication of this territorial issue concerns the Orontes river. The Orontes flows through Hatay, but Turkey is the downstream and Syria the upstream riparian in that basin. Yet there exists no satisfactory agreement over the Orontes river. A reason for this is that an agreement over the Orontes would imply the Syrian recognition of Hatay as a legitimate province of Turkey. Thus, water and territory constitute the main bones of contention in Turkish-Syrian relations. While the two neighbors negotiate over water rights but not over territorial change, the issue of terrorism remains the subject of open negotiations between them.

\section{The Issue of Terrorism}

The issue of terrorism between the two countries connects these other issues of contention. Both countries' perceptions are based on 
historical grievances and their beliefs about reciprocal policies conducted over the issues of water and support of terrorism (Beschorner, 1992, Bölükbasi, 1992; Cohen, 1992; Frey, 1993; Kut, 1993; Olson, 1992; Robins, 1991; Starr, 1991). These issues further complicate the conflict. The linkage between water and terrorism is similar to the inception of the PLO as a result of the second Arab meeting in Alexandria in 1964. This meeting took place after the Israeli National Water Carrier started its tests to pump water from Lake Tiberias, an important fresh-water reservoir in the Jordan basin. The PLO attacked the water pipeline from its bases in Jordan, causing Israeli retaliation (Lowi, 1993: 127). The Turkish project of GAP is also a target of a similar reaction. The Syrian support of the PKK is also partly aimed at the reduction or at least the delay of this project.

Repeated Turkish allegations and perception of Syrian support provided to the PKK demonstrate this complexity. The PKK aims at the establishment of a separate Kurdish state in the Turkish territory of Southeastern Anatolia and is engaged in armed attacks against the military and civilians. Turkey claims that the PKK headquarters are located in Syria and that the head of this organization resides in Damascus. Syrian officials affirm that they have granted the leader of the PKK asylum but they insist that, in conformity with the agreement reached in 1987 in Damascus during Turkish Prime Minister Turgut Özal's visit, they have forced the PKK to move its bases from Syrian territory to the Beqaa valley. Turkey does not have means of using the Kurds of Syria to retaliate in kind. The Kurds in Syria do not constitute a large part of the population like they do in Turkey and Iraq, and the Syrian regime tightly controls ethnic groups like the Turcomans and Kurds. To illustrate, following the recent military cooperation between Turkey and Israel, the Syrian government conducted mass arrests of Turcomans suspected of bombing attempts on its territory.

Despite the Turco-Syrian security arrangements, Turkey continued to accuse Syria of supporting the PKK, and Syria denied those accusations. For example, Turgut Özal's 1987 visit resulted in a major agreement whereby Turkey guaranteed a minimum water flow of 500 $\mathrm{cm} / \mathrm{s}$ and Syria promised cooperation in security matters. Few months later, Özal complained about terrorist activities in Turkey, and threatened Syria with cutting the water flow off.

The bilateral security agreements of 1992 and 1993 were not of much use either. In 1993, Tansu Çiller, the Turkish Prime Minister, in a message to Hafez Assad, the Syrian President, declared that Syria 
must prevent the PKK to operate on and from its territory, otherwise there could be no solution to the water problem. During the trilateral summit of February 1994 between the Foreign Ministers of Turkey, Iran, and Syria, Hikmet Çetin, the Turkish Foreign Minister, brought up again the issues of water and terrorism in his discussions with Faruk Al-Sara, his Syrian counterpart. These discussions did not improve bilateral relations either. Furthermore, the fleeing of PKK members to Syria in 1995 when Turkey organized military operations in northern Iraq confirmed Turkish suspicions. Hence, against this background of historical grievances and current developments, the issues of terrorism and water are still linked to each other in Turkish-Syrian relations. And the outcome of this issue-linkage is mutual conflict.

\section{THE MODEL}

The game tree in Figure 1 represents a simple one-shot game in extensive form which models the issue-linkage. Turkey and Syria are the players. Syria's uncertainty about Turkey's nature is the element of incomplete information. Turkey knows its own type, and it is aware of Syria's uncertainty. Syria knows in turn that Turkey is aware of its uncertainty about the Turkish dispositions towards mutual conflict.

\section{The Rules of the Game}

The game begins at the open node labeled $\mathrm{N}$ where Nature chooses Turkey's type, that is, Turkey's private information about the cost it incurs in the mutual conflict. Syria's prior beliefs represent its lack of information about the Turkish preference with respect to this cost. If Turkey suffers less from mutual conflict, then it is of the low-cost type (the Hard), and, if Turkey suffers more, then it is of the high-cost type (the Soft). Turkey can be the Hard or the Soft with probabilities $\mathrm{p}$ and $1-\mathrm{p}$, respectively.

Following Nature's move, Turkey chooses between accepting to sign a treaty, fixing a water quota for Syria or not. Syria moves after Turkey by deciding whether to support terrorist activities towards Turkey. Syria has two sets of information: the first contains the nodes that follow Turkish choices of agreement, the second those following no agreement. Thus, Syria can observe whether Turkey accepted to sign a treaty, but cannot distinguish between the Hard and the Soft. The game ends after Syria makes a choice.

Turkey is modeled as having the first move because, historically, Syria reacted to the hydroelectric developments upstream. The Syrian support of the PKK is a reaction to the Turkish water policy. 


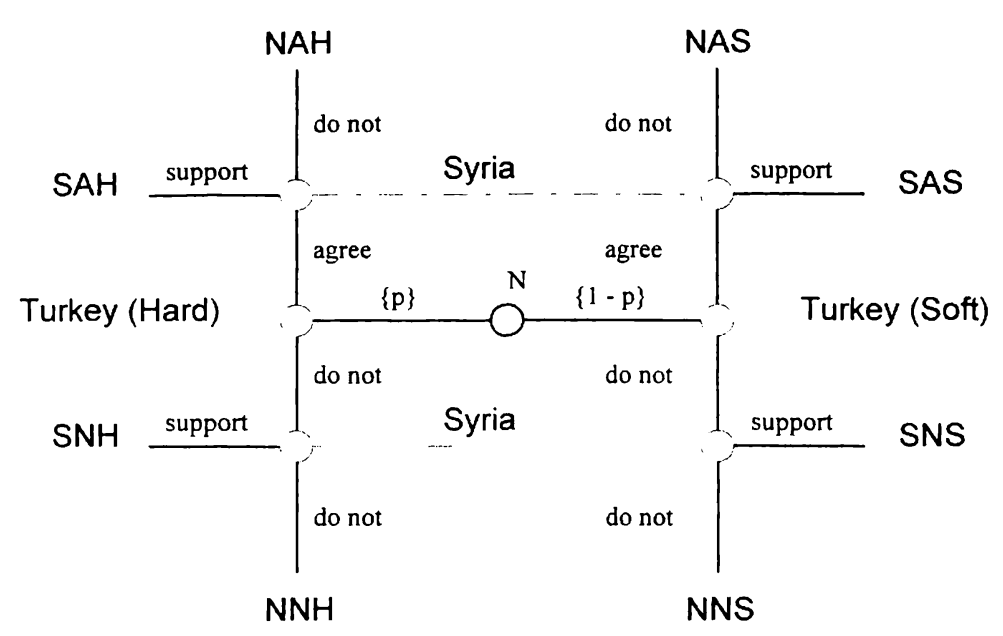

Figure 1

Also, Turkey has superior information since the Turkish resources in dealing with terrorism can change, given economic fluctuations. Another factor causing such an uncertainty is the relative volatility in the Turkish political system such as elections and coalition governments. The Turkish attitude with respect to the water issue can vary in function according to political changes within its democratic regime. There may be such Turkish governments making fundamental concessions to Syria to prevent its support of terrorism. For example, the senior partner of the actual Turkish coalition government, the Welfare Party, has a pro-islamic attitude, and its ascent to power may change the Turkish water policy. So, while some political parties may favor an intransigent attitude with respect to Syria, others might opt for a more cooperative policy. In contrast to Turkey, Syria has no democratic volatility but is ruled by an authoritarian regime. We, therefore, assume what is unknown to Syria is that how much Turkey can draw upon its potential resources to fight the PKK. The Hard continues the issue-linkage more effectively than the Soft.

The outcomes are SAH, NAH, NNH, SNH given that Turkey is the Hard and SAS, NAS, NNS, SNS given that Turkey is the Soft. If the Hard agrees to a treaty and Syria supports it, then the outcome is SAH. If the Hard agrees but Syria does not support it, then the outcome is NAH. If the Hard does not agree and Syria does not support it either, then NNH is the outcome. If the Hard does not agree to a treaty and Syria supports, then SNH is reached. The outcome of SAS is similar to SAH; Turkey agrees but Syria supports when Turkey is 
the Soft. The same similarity exists between NAH and NAS, SNH and SNS, NNH and NNS. The table 1 describes all outcomes.

Table 1

The Outcomes

\begin{tabular}{|l|l|}
\hline $\begin{array}{l}\text { Syria does not support, Turkey does not agree when } \\
\text { Turkey is respectively the Hard and the Soft }\end{array}$ & NNH, NNS \\
\hline $\begin{array}{l}\text { Syria does not support, Turkey agrees when Turkey } \\
\text { is respectively the Hard and the Soft }\end{array}$ & NAH, NAS \\
\hline $\begin{array}{l}\text { Syria supports and Turkey does not agree when } \\
\text { Turkey is respectively the Hard and the Soft }\end{array}$ & SNH, SNS \\
\hline $\begin{array}{l}\text { Syria supports and Turkey agrees when Turkey is } \\
\text { respectively the Hard and the Soft }\end{array}$ & SAH, SAS \\
\hline
\end{tabular}

The outcomes of NNH and NNS indicate Syrian unilateral concessions: they result from a Turkish refusal to agree followed by the Syrian choice of no support. The outcomes reached by no concessions represent the mutual conflict while bilateral concessions represent cooperation. So, the current status quo, that is, the mutual conflict, is obtained when no concessions are issued. These are the outcomes SNH and SNS. The outcomes reached by unilateral concessions $\mathrm{SAH}, \mathrm{SAS}, \mathrm{NNH}, \mathrm{NNS}$ represent that one riparian wins at the expense of the other.

\section{Utility Assumptions}

We assume that, whatever its type, Turkey prefers the Syrian unilateral concession most. In that case, Turkey suffers no cost at fighting terrorism and does not let flow more than $500 \mathrm{~cm} / \mathrm{s}$ of water to Syria. Turkey's least preferred outcome is its unilateral concession, as it flows more water than $500 \mathrm{~cm} / \mathrm{s}$ and, in response, Syria supports it. This outcome represents heavy costs but no gain at all. Such a preference ordering is in conformity with upstream riparians' general desire to keep sovereign control on the river flow by communicating its respect for downstream riparians' interest (Waterbury, 1990: 10). Declaring the principles of "no significant harm" and "equitable and reasonable utilization" underlie its three-stage plan; Turkey prefers a flexible arrangement to a commitment over water (Turkish Ministry of Foreign Affairs, 1994: 33).

An explicit Syrian move to prevent terrorist activities will also signal that Syria will not question Turkish sovereignty over Hatay. Turkey is highly suspicious that Syria will support terrorism after a 
water agreement to force it to concede Hatay in the long run. In other words, Turkey suspects that Syria aims at two objectives by its policy of backing separatist forces in its territory. In the 19 February 1995 issue of Turkish daily Cumhurivet, a Turkish diplomat indicated that Turkey does not want Syria to bring up the issue of Hatay after an agreement over water. The game tree thus describes the Syrian ability to deceive Turkey by continuing to support terrorism after a water agreement; otherwise we should not have Syria moving after Turkish agreement and the tree should close there. Hence, Turkey is not mindful only about a water allocation but also about being double crossed.

The difference between ordering of the mutual conflict and bilateral concessions determines the type of Turkey. The Soft incurs a greater cost than the Hard in fighting terrorism when it does not make a concession. The current status quo harms the Soft more than the Hard. Thus, the Hard's next-best and the next-worst outcomes are respectively the mutual conflict and to agree to the condition Syria does not support. For the Soft this ordering is reversed. The Soft prefers bilateral concessions to mutual conflict. Thus, the Turkish preference orderings are:

Turkey (Hard): $\mathrm{U}_{\mathrm{T}}(\mathrm{NNH})>\mathrm{U}_{\mathrm{T}}(\mathrm{SNH})>\mathrm{U}_{\mathrm{T}}(\mathrm{NAH})>\mathrm{U}_{\mathrm{T}}(\mathrm{SAH})$ Turkey (Soft): $\mathrm{U}_{\mathrm{T}}(\mathrm{NNS})>\mathrm{U}_{\mathrm{T}}(\mathrm{NAS})>\mathrm{U}_{\mathrm{T}}(\mathrm{SNS})>\mathrm{U}_{\mathrm{T}}(\mathrm{SAS})$.

These orderings represent Syria's uncertainty about Turkish dispositions with respect to mutual conflict. Syria does not know the type of Turkey with which it is dealing. It is uncertain about the cost Turkey incurs in fighting terrorism, but Turkey is fully informed about the Syrian support of terrorist activities. So, Syria has different preferences towards the two types. We assume that Syria perceives the Hard as more prone than the Soft to cut water or to take military measures if it continues to support the PKK after Turkey offers an agreement. It expects that the Hard has more incentives to punish its policy of a double cross. The Soft incurs higher costs than the Hard in responding to Syria's support once it agrees to a treaty. This also implies that Syria evaluates a mutual conflict with the Hard as being costlier than would it be with the Soft. Therefore, Syria's uncertainty creates a dilemma: if it were certain it faced the Hard, it would never support terrorism, otherwise it would. These Syrian expectations about the Turkish decision to cut water or to take military measures in retaliation to its continued support of terrorism after Turkey offers a water agreement are contained in the utilities $U_{S}$ $(\mathrm{SAH})$ and $\mathrm{U}_{\mathrm{S}}(\mathrm{SAS})$. The Syrian preference orderings are: 


$$
\begin{gathered}
U_{s}(S A S)>U_{S}(S A H), U_{s}(N A S) \\
U_{s}(N A H)>U_{s}(S A H), U_{S}(N A S) \\
U_{S}(N N H)>U_{S}(N N S), U_{S}(S N H) \\
U_{S}(S N S)>U_{S}(S N H), U_{S}(N N S)
\end{gathered}
$$

The first ordering means that Syria rather prefers to deceive on the Soft than on the Hard, as the Hard is more prone to punish Syria in that case. After the Soft agrees, Syria prefers to cheat than to discontinue its support. In contrast, the second ordering means that Syria prefers bilateral cooperation to cheating after the Hard agrees and that the bilateral cooperation with the Hard is of greater value than with the Soft for Syria. The third one indicates that Syria prefers to give a unilateral concession if it confronts the Hard, and that Syria prefers halting its support of terrorism if the Hard does not agree. The final ordering indicates that the mutual conflict with the Hard is less desirable than with the Soft. These orderings clarify why Syria's utilities depend on Turkey's private information.

\section{THE EQUILIBRIA}

To find the perfect Bayesian equilibria we follow three steps: propose a pair of strategies, compute the beliefs they generate, and establish that these strategies are the best replies against each other given beliefs they generate (Rasmusen, 1989: 59). Accordingly, we propose the Turkish strategy of not agreeing whether it is the Hard or the Soft. Let $\theta$ denote Syria's belief that it is at the lower-left node of its information set reached by the Turkish refusals to agree. Therefore, (1- $\theta$ ) denotes its belief that it is at the lower-right node in the same information set. Hence, $\theta$ is Syria's belief that Turkey is the Hard and $(1-\theta)$ is its belief that Turkey is the Soft, if Turkey refused to agree. Syria updates its priors about Turkey's type $\{p,(1-p)\}$ to obtain its beliefs (or posteriors) given the Turkish action. These are computed by Bayes' rule and Turkey's proposed strategy:

$$
\theta=p\left(T_{h}:-a\right)=\frac{p\left(-a: T_{h}\right) p\left(T_{h}\right)}{p\left(-a: T_{h}\right) p\left(T_{h}\right)+p\left(-a: T_{s}\right) p\left(T_{s}\right)}
$$

where $T_{h}$ denotes the Hard, $T_{s}$ the Soft, $-a$ the Turkish refusal to agree, $p\left(T_{h}\right)$ the Syrian belief that Turkey is the Hard, $p\left(T_{s}\right)$ the Syrian belief that Turkey is the Soft, $p\left(-a: T_{h}\right)$ the conditional probability that Turkey does not agree given it is the Hard, $p\left(-a: T_{s}\right)$ the conditional probability that Turkey does not agree given it is the Soft, and $p\left(T_{1 / \text { :- }}\right.$ a) is the conditional probability that Turkey is the Hard given that it did not agree. 
We have $p=p\left(T_{h}\right)$ and 1-p $=p\left(T_{s}\right)$. Suppose Th refuses with $1-q_{1}$ and $\mathrm{T}_{s}$ with 1-q2. Thus:

$$
\theta=p\left(T_{h}:-a\right)=\frac{\left(1-q_{1}\right) p}{\left(1-q_{1}\right) p+\left(1-q^{2}\right)(1-p)}
$$

We have $1-q_{1}=1-q_{2}=1$ in this pooling equilibrium, and

$$
\theta=p\left(T_{h}:-a\right)=\frac{p}{p+1-p}=p
$$

Syria is going to compare its expected payoffs from supporting and not supporting given these beliefs. Syria's expected utility from support given that Turkey did not agree is:

$$
E U_{s}(s:-a)=\theta U_{s}(S N H)+(1-\theta) U_{s}(S N S)=p U_{s}(S N H)=(1-p) U_{s}(S N S)
$$

Syria's expected utility from not supporting given Turkey did not agree is:

$$
E U_{s}(-s:-a)=\theta U_{s}(N N H)+(1-\theta) U_{s}(N N S)=p U_{s}(N N H)+(1-p) U_{s}(N N S)
$$

where $-s$ denotes the Syrian action of not supporting terrorism. If Syria's expected utility of not supporting is greater than the one supporting if Turkey did not agree, then Syria will not support terrorism. This is equivalent to:

$$
E U_{s}(-s:-a)>E U_{s}(s:-a)
$$

This implies:

$$
p U_{s}(N N H)+(1-p) U_{s}(N N S)>p U_{s}(S N H)+(1-p) U_{s}(S N S)
$$

Hence:

$$
p>\frac{U_{s}(S N S)-U_{s}(N N S)}{U_{s}(S N S)-U_{s}(N N S)+U_{s}(N N H)-U_{s}(S N H)}
$$

By letting

$$
\alpha=\frac{U_{s}(S N S)-U_{s}(N N S)}{U_{s}(S N S)-U_{s}(N N S)+U_{s}(N N H)-U_{s}(S N H)}
$$


we can rewrite this condition as:

$$
p>\alpha
$$

The assumptions about Syrian utilities imply that $\alpha<1$. Thus, if $p$ satisfies the condition (2), then Syria's best reply against the Turkish choice of non-agreement is not to support, or support otherwise.

We can rewrite the equation (1) as

$$
\alpha=\frac{x}{x+y}
$$

by letting $x=U_{s}(S N S)-U_{s}(N N S)$ and $y=U_{s}(N N H)-U_{s}(S N H)$.

Hence we also have $\lim z \rightarrow \infty \beta=\lim w \rightarrow 0 \beta=0, \lim y \rightarrow \infty \alpha=$ $\lim x \rightarrow 0 \alpha=0$, and $\lim y \rightarrow 0 \alpha=\lim x \rightarrow \infty \alpha=1$.

Suppose $\mathrm{p}$ satisfies the condition (2). As a result, Turkey obtains $\mathrm{U}_{\mathrm{T}}(N N H)$ and $\mathrm{U}_{\mathrm{T}}(N N S)$. Now, we have to calculate Syria's beliefs off the equilibrium path to assess its reaction to the Turkish deviation from the proposed equilibrium strategy. Again, Syria is going to compare its expected payoffs from supporting or not supporting.

Let $\mu$ denote Syria's belief that it is at the upper-left node of its information set reached by the Turkish agreement and (1- $\mu)$ its belief that it is at the lower-right node in the same information set. Hence, $\mu$ is Syria's belief that Turkey is the Hard and $(1-\mu)$ its belief that Turkey is the Soft given that Turkey signed an international treaty. Upon Turkish action, Syria is going to update its priors about Turkey, $\{p,(1-p)\}$, to obtain its beliefs off-the-equilibrium path. These are again computed by Bayes' rule and Turkey's proposed strategy:

$$
\mu=p\left(T_{h}: a\right)=\frac{p\left(a: T_{h}\right) p\left(T_{h}\right)}{p\left(a: T_{h}\right) p\left(T_{h}\right)+p\left(a: T_{s}\right) p\left(T_{s}\right)}
$$

where a denotes the Turkish choice of agreement, $p\left(a: T_{h}\right)$ is the conditional probability that Turkey agrees given it is the Hard, $p\left(a: T_{s}\right)$ is the conditional probability that Turkey agrees given it is the Soft, $p\left(T_{l l}: a\right)$ is the conditional probability that Turkey is the Hard given that it agreed. We again have $p\left(T_{h}\right)=p$ and $p\left(T_{s}\right)=(1-p)$. We have $T_{h}$ agrees with $q_{1}$ and $T_{s}$ agrees with $q_{2}$ probability. Thus:

$$
\mu=p\left(T_{h}: a\right)=\frac{q_{l} p}{q_{l} p+q_{2}(1-p)}
$$

We have $\mathrm{q}_{1}=\mathrm{q}_{2}=1$ in this deviation from the proposed equilibrium, and: 


$$
\mu=p\left(T_{h}: a\right)=\frac{p}{p+1-p}
$$

Syria is going to compare its expected payoffs from supporting or not supporting given these beliefs. Syria's expected utility from supporting given Turkey agreed is:

$$
E U_{s}(s: A)+\mu U_{s}(S A H)+(1-\mu) U_{s}(S A S)=p U_{s}(S A H)+(1-p) U_{s}(S A S)
$$

Syria's expected utility from not supporting given Turkey agreed is:

$$
E U_{s}(-s: a)=\mu U_{s}(N A H)+(1-\mu) U_{s}(N A S)=p U_{s}(N A H)+(1-p) U_{s}(N A S)
$$

If Syria's expected utility of not supporting is greater than the one of supporting given that Turkey agreed, then Syria will not support terrorism. This is equivalent to:

$$
E U_{s}(-s: a)>E U_{s}(s: a)
$$

This implies:

$$
p U_{s}(N A H)+(1-p) U_{s}(N A S)>p U_{s}(S A H)+(1-p) U_{s}(S A S)
$$

Hence:

$$
p>\frac{U_{s}(S A S)-U_{s}(N A S)}{U_{s}(S A S)-U_{s}(N A S)+U_{s}(N A H)-U_{s}(S A H)}
$$

By letting

$$
\beta=\frac{U_{s}(S A S)-U_{s}(N A S)}{U_{s}(S A S)-U_{s}(N A S)+U_{s}(N A H)-U_{s}(S A H)}
$$

we can rewrite this condition as

$$
p>\beta
$$

The assumptions about Syrian utilities imply that $\beta<1$. Thus, if $p$ satisfies the condition (4), then Syria's best reply against Turkish agreement is not to support, or support otherwise.

We can rewrite the equation (3) as

$$
\beta=\frac{w}{w+z}
$$


by letting $U_{s}(S A S)-U_{s}(N A S)=w$ and $U_{s}(N A H)-U_{s}(S A H)=z$. Hence we also have $\lim _{z} \rightarrow \infty \beta=\lim _{w} \rightarrow$ o $\beta=0$, and, $\lim _{z} \rightarrow$ o $\beta=\lim _{w}$ $\rightarrow \infty \beta=1$.

Suppose $\mathrm{p}$ satisfies the condition (4). As a result, Turkey obtains $U_{T}(N A H)$ and $U_{T}(N A S)$. By assumption $U_{T}(N N H)>U_{T}(N A H)$ and $U_{T}(N N S)>U_{T}(N A S)$. Therefore, Turkey (either the Hard or the Soft) has no incentive to switch from its equilibrium strategy. Pooling on no agreement is a part of the equilibrium strategy profile with Syria's best replies being not to support whatever Turkey does with beliefs satisfying the conditions (2) and (4). This is the first equilibrium.

We can summarize the combinations of Syrian beliefs leading to its best replies in the following table that introduces the following notation for Syria's best replies:

$r_{1}=$ The probability that Syria responds by supporting when Turkey agrees,

$r_{2}=$ the probability that Syria responds by supporting when Turkey does not agree,

$1-r_{1}=$ the probability that Syria responds by not supporting when Turkey agrees,

$1-r_{2}=$ the probability that Syria responds by not supporting when Turkey does not agree.

Table 2

Syrian Best Replies

\begin{tabular}{|ccc|}
\hline & $p>\alpha$ & $p \leq \alpha$ \\
\hline$p>\beta$ & $r_{1}=0 ; 1-r_{1}=1$ & $r_{1}=0 ; 1-r_{1}=1$ \\
& $r_{2}=0 ; 1-r_{2}=1$ & $r_{2}=1 ; 1-r_{2}=0$ \\
& $(-s,-s)$ & $(-s, s)$ \\
\hline$p \leq \beta$ & $r_{1}=1 ; 1-r_{1}=0$ & $r_{1}=1 ; 1-r_{1}=0$ \\
& $r_{2}=0 ; 1-r_{2}=1$ & $r_{2}=1 ; 1-r_{2}=0$ \\
& $(s,-s)$ & $(s, s)$ \\
\hline
\end{tabular}

The first letter in parentheses refers to the Syrian response to the Turkish agreement, and the second to the Turkish refusal to agree to a treaty. This table facilitates the description of equilibria below.

\section{Equilibrium 1}

Propose $(-a,-a)$. If $p>\alpha$, then $r_{2}=0$. Turkey obtains $U_{T}(N N H)$ and $U_{T}(N N S)$. Suppose $p>\alpha$. To understand whether both types want to choose no agreement we have to compute how Syria reacts to the Turkish deviation from the proposed equilibrium strategy. In its 
information set off-the-equilibrium path, if $p>\beta$, then $r_{1}=0$. The Syrian best reply is not to support if Turkey agrees. Suppose also $p>\beta$. Thus, Turkey obtains $U_{T}(N A H)$ and $U_{T}(N A S)$.

However, we have $U_{T}(N N H)>U_{T}(N A H)$ and $U_{T}(N N S)>U_{T}(N A S)$. Therefore, Turkey has no incentive to deviate from its strategy. Hence, $\{(-a,-a),(-s,-s), p>\alpha, \beta\}$ is a pooling equilibrium.

\section{Equilibrium 2}

Propose $(-a,-a)$. If $\mathrm{p}>\alpha$, then $\mathrm{r}_{2}=0$. Turkey obtains $U_{\mathrm{T}}(N N H)$ and $U_{\mathrm{T}}(N N S)$. Suppose $p>\alpha$. Now compute how Syria reacts to the Turkish deviation. In its information set off-the-equilibrium path, if $\mathrm{p} \leq \beta$, then $\mathrm{r}_{1}=1$. Suppose $\mathrm{p} \leq \beta$. The Syrian best reply is to support if Turkey agrees. Thus, Turkey obtains $U_{T}(S A H)$ and $U_{T}(S A S)$.

However, we have $U_{T}(N N H)>\mathrm{U}_{T}(S A H)$ and $U_{T}(N N S)>U_{T}(S A S)$. Turkey has, again, no incentive to deviate from its strategy. Therefore, $\{(-a,-a),(-s,-s), \beta \geq \mathrm{p}>\alpha\}$ is a pooling equilibrium.

\section{Equilibrium 3}

Propose $(-\mathrm{a},-\mathrm{a})$. If $\mathrm{p} \leq \alpha$, then $\mathrm{r}_{2}=1$. Turkey obtains $U_{T}(\mathrm{SNH})$ and $U_{T}$ (SNS). Suppose $\mathrm{p} \leq \alpha$. Now compute how Syria reacts to the Turkish deviation. In its information set off-the equilibrium path, if $p \leq \beta$, then $r_{1}=1$. The Syrian best reply is to support if Turkey agrees. Suppose also $p \leq \beta$. Thus, Turkey obtains $U_{T}(\mathrm{SAH})$ and $U_{T}(\mathrm{SAS})$.

However, we have $U_{T}(\mathrm{SNH})>\mathrm{U}_{T}(\mathrm{SAH})$ and $U_{T}(\mathrm{SNS})>\mathrm{U}_{T}(\mathrm{SAS})$. Therefore, Turkey has no incentive to deviate from its strategy. Hence, $\{(-a,-a),(-s,-s), \alpha, \beta \geq p\}$ is a pooling equilibrium.

\section{DISCUSSION}

Overall, if $\alpha>p>\beta$ (hence $\alpha>\beta$ ), Syria supports the PKK when Turkey does not agree but ceases to support them when Turkey agrees. A strategy profile where both types do not agree is not part of a pooling equilibrium, as the Soft has an incentive to switch from not to agree to agree as $U_{T}(N A S)>U_{T}(S N S)$. Similarly, a strategy profile where both types agree is not part of a pooling equilibrium, as the Hard has an incentive to switch from agreeing to not to agree as $U_{T}(S N H)>U_{T}(N A H)$.

If we propose the equilibrium where the Hard does not agree but the Soft does, then the Hard obtains its best outcome as Syria gives in unilaterally. The Soft, on the other hand, obtains its worst outcome as Syria double crosses. The Soft has then an incentive to deviate from the proposed equilibrium strategy to obtain its next-worst out- 
come, that is, the status quo. In a proposed equilibrium where the Hard agrees but the Soft does not, the Hard obtains its next-worst outcome as the result of bilateral concessions. The Hard has in turn an incentive to switch to no agreement. Hence, there is no separating equilibrium where one type finds it beneficial to agree.

Consequently, Syria must be aware that the Soft will not take any action that will reveal its relative weakness in the issue-linkage. Put differently, Syria should not expect that the difference in Turkish sensitivity to the cost it suffers in the status quo will lead to diametrically opposed Turkish positions. This also implies that, in the future, Turkey will still prefer no concessions unless its preferences change so that it will find an agreement beneficial. Such a change may occur if Turkey does not perceive the whole issue as a matter of sovereignty given the Syrian policy. This is a remote possibility.

In contrast, regardless of the cost it suffers from the status quo, Turkey finds it beneficial not to agree. In the first equilibrium, Syria's best reply is not to support terrorism if Turkey agrees or not. In other words, Turkey knows Syria will halt its support given its water policy and consequently offers no agreement. In the second equilibrium, Syria's best reply is to deceive and to halt its support if Turkey does not agree. This means that Turkey does not offer an agreement because it knows Syria does not support if it refuses to agree, otherwise Syria cheats by asking further concessions after an agreement. In the third equilibrium, Syria's best reply is to support terrorism regardless of the Turkish water policy. This is due to Syria's underestimation of the Turkish ability to sustain the current status-quo. We now need an index that will facilitate our interpretation and discussion of these equilibria.

Huth (1988) tests hypotheses about the relationship between the balance of capabilities and deterrence by constructing several indices such as the long-term and the short-term balances. He measures the long-term balance between two countries by their overall military and industrial capacities, and the short-term balance by their standing and ground air-forces. He also argues that the long-term balance affects the calculations about wars of attrition. In our analysis, these balances approximate Syrian beliefs.

In the Turkish-Syrian conflict, the status quo indicates a war of attrition. Both countries suffer in the mutual conflict. As to the military balance between the two countries, we observe that Syria is one of the strongest states in the Middle East. Especially, the percentage of its GDP Syria devotes to armament efforts (in order to match 
Israeli capabilities) is nearly three times higher than Turkey since the 1980s (Deger and Sen, 1990). Consequently, Syria's air-force, airreconnaissance ability, armed vehicles, and fire capacity are not inferior to Turkish capabilities. Thus, we can reasonably argue that Syria holds the belief that a mutual conflict is very costly for Turkey. It probably perceives Turkey more as the Soft than as the Hard. Turkey's actual foreign policy towards Syria is one that can only reinforce this Syrian belief. Turkey does not pursue a resolute policy by reacting severely to its downstream neighbor's territorial claims and continuous policy of denial and deception.

The thresholds $\alpha$ and $\beta$ depend upon different utilities Syria obtains. The former pertains to the Syrian information set containing nodes that follow Turkish choices of no agreement and the latter pertains to the one that contains those nodes that follow Turkish choices of agreement. Therefore, threshold $\alpha$ depends on the utilities Syria obtains from the status quo and its unilateral concession. Threshold $\beta$ depends in turn on the utilities Syria obtains from cooperation and Turkey's unilateral concession. More precisely, the nominator $\alpha$ measures the relative value of the status quo with respect to not supporting when Turkey is the Soft and the Soft does not agree. Its denominator is the sum of the term in the nominator and the relative value of not supporting terrorism with respect to the status quo when Turkey is the Hard. The nominator of $\beta$ measures the relative value of Turkey's unilateral concession with respect to cooperation when Turkey is the Soft. Its denominator is the sum of the term in the nominator and the relative value of cooperation with respect to Turkey's unilateral concession when Turkey is the Hard.

The threshold $\alpha$ is closer to zero if and only if not supporting terrorism provides greater utility than supporting given that the Hard did not agree. It is closer to one if and only if not supporting provides a lesser utility than supporting given that the Soft did not agree. Similarly, the threshold $\beta$ is closer to zero if and only if cooperation (bilateral concessions) provides greater utility than supporting given that the Hard agreed. It is closer to one if and only if cooperation provides lesser utility than supporting given that the Soft agreed. Therefore, in cases where both thresholds are high, there is a lesser chance for the Syrian prior that Turkey is the Hard (p) to exceed them. As the Syrian prior and the thresholds are smaller than one, higher thresholds mean that the interval where the prior exceeds them shrinks; otherwise it expands. Similarly, in cases where both thresholds are low, there is a higher chance for the Syrian prior to exceed 
them. Hence, high thresholds imply that the Syrian support is more likely and low thresholds imply that the Syrian support is less likely. The military balance reduces both the relative value of the Syrian unilateral concession with respect to the status quo, and the relative value of cooperation with respect to the Turkish unilateral concession when Turkey is the Hard. This only increases both $\alpha$ and $\beta$, making it more difficult for $\mathrm{p}$ to exceed them.

Consequently, the third equilibrium reflects the current status quo and is confirmed by the empirical analysis. Turkey does not agree to sign a water treaty and Syria supports the PKK. We can relax the assumptions of preference orderings to discover the conditions of a water agreement as desired by Syria. The change in Turkish preferences such that the Hard prefers mutual concessions to mutual conflict and that the Soft prefers a unilateral concession to mutual conflict, while holding Syrian preferences fixed, makes such an agreement a possibility. As a result, Turkey finds it indeed beneficial to agree when it either suffers a high or a low cost in the issue-linkage. One then obtains a pooling equilibrium in which Turkey agrees. Syria's best reply is not to cheat but to retaliate against the Turkish refusal by supporting, and to cease its support when Turkey agrees $(\beta<p$ $\leq \alpha$ ). Hence, given a Turkish agreement, Syria believes that Turkey is sufficiently weak, but obtains higher expected payoffs by not cheating or by retaliating. However, as argued before, such changes of Turkish preferences are questionable. Turkey at least would never accept to concede unilaterally given Syria's continuous policy of supporting terrorism and its aim to annex Hatay in the future.

In sum, all three equilibria describe different motives for the consistent Turkish water policy. Therefore, whether Syria gives the impression that it believes Turkey is the Soft or the Hard makes no difference. Such beliefs do not provide any incentives for Turkey to agree. Assuming that Syria's belief $p$ increases as the Turkish capabilities increase relative to its own, a balance either favoring Turkey or Syria will only change Syria's best replies, not the Turkish signal. The long-term and the short-term balances between the two countries only change Syria's policy. Turkey's policy is unaffected by them.

As the third equilibrium reflects current relations between the two countries, and, as Turkey knows Syria's uncertainty and Syria knows that Turkey knows its uncertainty (and so on) whether it faces the Hard or the Soft, the Syrian negotiators should assess that their Turkish counterparts evaluate that the war of attrition is not too costly for Syria even if they think Syria perceives Turkey as the Hard. This could only affirm for the Turkish negotiators that there is a way, 
as the first equilibrium suggests, to obtain a Syrian unilateral conces-sion: to cause, through communication, a Syrian perception of a mutual conflict being too costly and a bilateral cooperation being relatively desirable with respect to cheating the Hard. Given no changes in Turkish preferences in the long term, such a concession could pave the way to obtain cooperation over the waters of the Euphrates.

\section{CONCLUSION}

This article has examined the implications of the water-terrorism issue-linkage against the background of the territory issue between Turkey and Syria in the framework of a simple signalling game. I have shown that three equilibria may occur, but only one of them explains the observed pattern. The other two equilibria reveal that Turkey's best reply does not change even if Syria's best replies change according to different Syrian beliefs.

Overall, a Turkish-Syrian agreement over the Euphrates is found to be an impossibility. This result does not change by allowing Syrian beliefs to vary. Hence, assuming the preference orderings will accurately reflect countries' positions, changes in the military capabilities taken as proxies of beliefs do not change the outcome. It is unlikely that Syria's aim over Hatay will change. The same is valid for the Turkish perception regarding revisionist Syrian policies. Further, there is no sign that these preferences will misrepresent the reality in the future.

There are several possibilities to extend the model. One extension could be the inclusion of the PKK as a third player, which might imply the possibilities of a PKK-Syrian dissent about their common policy with respect to Turkey. Syria may decide to lower the costs of terrorism for Turkey and the PKK may not coordinate its activities along such a Syrian policy. Another one is to present this extension within the context of a two-sided incomplete information where both Syria and Turkey misperceive their respective preference orderings. Also, noting the similarity between the Israeli National Water Carrier and the Turkish project GAP, the model developed in this paper could also apply to the developments in the Jordan basin prior to the 1967 war. However, unlike the lake Tiberias, the GAP has never been the subject of an arrangement like the Unified Plan aimed at the partitioning of the waters of the Jordan river basin. So, one must be aware of those differences in the basins of Jordan and Euphrates concerning the number of players, their water resources, and their preferences. 
I would like to conclude with two broader remarks. The analysis suggests that if Syria desires cooperation with Turkey, then it has to forego its territorial claims. Such a policy reversal may positively affect Turkish preferences so that Turkey would be more prone to cooperation without suspecting that it will be double-crossed. The Syrian aim to extract a concession over both territory and water through supporting terrorism is pitched at such a level that it does not generate any incentive for cooperation in the basin. Moreover, it is not an exaggeration to indicate that the Israeli-Syrian conflict indirectly lowers in the eyes of Syrians the Turkish ability to sustain this costly issue-linkage. Trying at least to achieve some military parity with Israel and bolstering its armament efforts, Syria does not perceive Turkey as being militarily powerful. Paradoxically, such a perception only fuels a Syrian policy of territorial claim and of terrorism that, in turn, makes Turkey more intransigent.

\section{ACKNOWLEDGMENTS}

I am indebted to Nedim Alemdar, Mehmet Baç, and Nur Bilge Criss for their help and suggestions. An earlier version of this paper was presented at the International Conference on Game Theory and Applications, organized in honor of Robert J. Aumann on his 65th birthday, Jerusalem, Israel, June 25-29, 1995.

\section{REFERENCES}

Beschorner, Natasha. (1992) "Water and Instability in the Middle East." Adelphi Paper, no.273 (Winter). London: The International Institute for Strategic Studies.

Bilen, Özden. (1993) "Prospects for Technical Cooperation in the Euphrates and Tigris Basin." unpublished ms., Ankara: General Directorate of State Hydraulic Works.

Bölükbasi, Suha. (1993) "Turkey Challenges Iraq and Syria: the Euphrates Dispute." Journal of South Asian and Middle Eastern Studies, vol.16, no.4 (summer), pp.9-32.

Cohen, Jonathan E. (1992) "International Law and the Water Politics of the Euphrates." New York University Journal of International Law and Politics, vol.24, no.1, pp.503-557.

Deger, Saadet and Somnath Sen. (1990) Military Expenditures: the Political Economy of International Security. SIPRI (Stockholm International Peace Research Institute) Oxford: Oxford University Press.

Dinar, Ariel and Dan Yaron. (1986) "Sharing Regional Cooperative Gains From Reusing Effluent for Irrigation." Water Resources Research, vol.22, no.3 (March), pp.339-344.

Frey, Frederic. (1993) "The Political Context for Conflict and Cooperation Over International River Basins." Water International, vol.18, no.1, pp.54-68. 
Huth, Paul. (1988) Extended Deterrence and the Prevention of War. New Haven, Connecticut: Yale University Press.

Kilgour, D. Marc and Ariel Dinar. (1994) "Are Stable Agreements for Sharing International River Waters Now Possible?" Paper prepared for the 36th Annual Convention of the International Studies, Chicago, Illinois, 21-25 February 1995.

Kut, Gün. (1993) "Burning Waters: the Hydropolitics of the Euphrates and Tigris." New Perspectives on Turkey, Fall, no.9, pp.1-17.

LeMarquand, David G. (1977) International Rivers: The Politics of Cooperation. Vancouver, B.C.: Westwater Research Centre, University of British Columbia.

Lowi, Miriam R. (1993) Water and Power: The Politics of a Scarce Resource in the Jordan Basin. Cambridge: Cambridge University Press.

Olson, Robert. (1992) "The Kurdish Question in the Aftermath of the Gulf War: Geopolitical and Geostrategic Changes in the Middle East." Third World Quarterly, vol.13, no.3, pp.475-499.

Rasmusen, Eric. (1989) Games and Information: An Introduction to Game Theory. Cambridge, Massachusetts: Basic Blackwell.

Republic of Turkey. Ministry of Foreign Affairs. (1994) "Water Issues Between Turkey, Syria, and Iraq." Report prepared by the Department of Regional and Transboundary Waters, Ankara.

Robins, Phillip. (1991) Turkey and the Middle East. London: Pinter.

Rogers, Peter. (1993) "The Value of Cooperation in Resolving International River Basin Disputes." Natural Resources Forum, vol.17, no.2 (May), pp.117-131.

Starr, Joyce. (1991) "Water Wars." Foreign Policy, vol.82, pp.17-36.

Tijs, H. and Theo Driessen. (1986) "Game Theory and Cost Allocation Problems." Management Science, vol.32, no.8 (August), pp.1015-1028.

Waterbury, John. (1990) "Dynamics of Basin-Wide Cooperation in the Utilization of the Euphrates." (Paper prepared for the conference, The Economic Development of Syria: Problems, Progress, and Prospects, Damascus, 6-7 January 1990).

Young, Peyton H, N. Okida, and T. Hashimoto. (1982) "Cost Allocation in Water Resources." Water Resources Research, vol.18, no.3 (June), pp.463-475. 